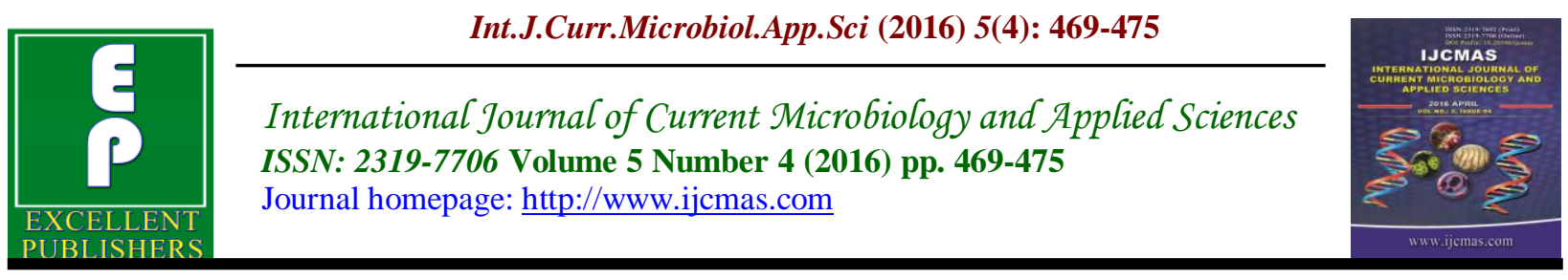

Original Research Article

http://dx.doi.org/10.20546/ijcmas.2016.504.055

\title{
Phytochemical Analysis and Anti-Oxidant Activity of Gold Nanoparticles Synthesizing Plant - Silybum marianum
}

\author{
D. Kosalai and M. Chandran* \\ Department of Zoology, Thiruvalluvar University, Vellore, India \\ *Corresponding author
}

\begin{abstract}
A B S T R A C T
Keywords

Anti-oxidant,

Gold

nanoparticles,

Silybum

marianum.

\begin{tabular}{l}
\hline Article Info \\
\hline Accepted: \\
16 March 2016 \\
Available Online: \\
10 April 2016
\end{tabular}

The use of nanoparticle in the field of medicine is increasing in the present world of technology. That too, green synthesis of nanoparticle has attracted scientist as a safe, easy and cheap mode of nanoparticle production in the developing and also in developed countries. In the present study, the gold nanoparticles were synthesized using the medicinal plant Silybum marianum. It is used from the ancient period for treating several liver disorders. The plant has been tested for its phytochemical constituents using standard procedures and was found to have flavonoids, alkaloids and anthocyanins. The synthesized gold nanoparticles was tested for its antioxidant activity using several assays such as DPPH free radical scavenging assay, Superoxide free radical scavenging activity, Anti-lipid peroxidation assay and Hydrogen Peroxidase scavenging activity. The antioxidant activity result showed that the extract of Silybum marianum has notable effect on suppressing oxidation and thus oxidants.
\end{abstract}

\section{Introduction}

Nanoparticle is a unique subset of the broad field called as nanotechnology. Nanoparticles are those unagglomerated particles ranging in size from $10 \mathrm{~nm}$ to 500 nm. These nanoparticles are gaining importance in the present day technology due to its use in various fields such as medicine, drug delivery, information, energy and environmental technologies [1, 2]. Nanoparticles can be classified into two types viz engineered nanoparticles and nonengineered nanoparticles. Engineered nanoparticles are those created or synthesized artificially such as silver nanoparticles, gold nanoparticles etc for their use in several techniques where as nonengineered nanoparticles are those that are freely available in the environment such as atmospheric nanoparticles that are produced during combustion, aerosols etc. Both engineered and non-engineered nanoparticles pose their uses in several industries. Several techniques have been developed to synthesize nanoparticles such as chemical mediated synthesis, gas and liquid phase process etc [2]. Despite these "Biosynthesis" or "Green synthesis of nanoparticle has been growing from last 
decade to develop eco friendly technologies in material synthesis [3].

Biosynthesis or Green synthesis of nanoparticle has been considered as a perfect alternative for the chemical mediated synthesis due to their cheap cost and economically benign nature. Further the chemical and physical synthesis of nanoparticles was found to involve hazardous materials and leaves toxicity to nature [3]. Green synthesis using plant extracts is increasing when compared to synthesis mediated by microorganisms such as bacteria, algae and fungi because of their pathogenicity and elaborative cell culture maintaining process $[1,3]$. The use of plants for the preparation of nanoparticles could be more advantageous, because it does not require elaborate processes such as intracellular synthesis and multiple purification steps or the maintenance of microbial cell cultures. Several plants and their parts have been successfully used for the extracellular synthesis of metal nanoparticles such as Elaeagnus latifolia [4], Tinospora crispa [5], Phyllanthus niruri [6], Amaranthus spinosus [7], Ananus comosus [3], Embilca officinalis [8], Tamarindus indica [8], Ficus microcarpa [9] etc.

In the present study, green synthesis is mediated by the plant Silybum marianum. Silybum marianum is otherwise called as Cardus mariamus [11]. Its common name is Milk thistle in English and deve dikeni in Turkish [10, 11]. The plant is highly used for treating liver disorders. A roman nanturalist described milk thistle as "Excellent for carrying off bile". The plant contains several flavanolignans such as silybin, silymarin, silydianin and silychristine. Silymarin was found to be the highly present and effective compound in treating several liver disorders such as
Amanita mushroom poisoning, Hepatitis, Alcoholic liver disease and cirrhosis, Hyperchloesterolemia, Psoriasis etc [10]. A study on the plant also revealed its hepatoprotective property [11]. In the present study, the phytochemical properties of the plant have been analyzed and its extract was used for the green synthesis of gold nanoparticles.

\section{Materials and Methods}

\section{Sample Collection}

Fresh leaves of Silybum marianum was collected from in and around Conoor, Tamilnadu, India. Primarily the leaves were washed with mercuric chloride and dried with water absorbent paper. Then they were cut into small pieces and dispensed in $100 \mathrm{ml}$ of sterile distilled water and boiled for one hour at $80^{\circ} \mathrm{C}$. The extract was collected in separate conical flasks by typical filtration process [8].

\section{Extraction}

The collected leaves were washed with double distilled water and shadow dried before being grinded to fine powder and sieved to remove coarse particles. One gram leaf powder was mixed with $100 \mathrm{ml}$ of methanol and the mixture was left in a shaking incubator operating at $200 \mathrm{rpm}$, $25^{\circ} \mathrm{C}$ for $24 \mathrm{~h}$. The extract was then filtered and the filtrate was used for AuNPs synthesis [8].

\section{Phytochemical Analysis of Plant Extracts}

Phytochemical analysis of methanolic plant extracts have been done for glycosides, flavanoids, tannins, alkaloids, sugars, starches, saponins, proteins, aminoacids, terpenoids, vitamin $\mathrm{C}$ and phenolic 
compounds using the standard procedure $[12,13]$.

\section{Biosynthesis of Gold Nanoparticles}

Choloroauric acid (HAuCl4) solutions of 10

${ }^{3} \mathrm{M}$ were prepared for the synthesis of gold nanoparticles. $0.2 \mathrm{ml}$ of leaf extract was added to $50 \mathrm{ml}$ of $10^{-3} \mathrm{M} \mathrm{HAuCl} 4$ solution [3].

\section{DPPH Free Radical Scavenging Activity} Assay

An aliquot of the samples was mixed with DPPH solution $(5 \mu \mathrm{mL}, 23.6 \mu \mathrm{g} / \mathrm{mL}$ in ethanol), followed by incubation of $30 \mathrm{~min}$. The absorbance of each sample was read at $517 \mathrm{~nm}$. Ascorbic acid (0.9, 1.9, 3.9, 4.9, 6.9 $\mu \mathrm{g} / \mathrm{mL}$ ) was used as positive reference. The percentage of scavenged DPPH was calculated using equation 1 :

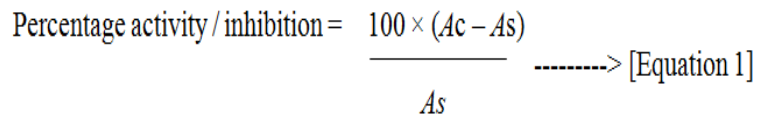

Where $A \mathrm{c}$ is the absorbance of the control and $A s$ is the absorbance of the sample. IC50 values calculated denote the concentration of the sample required to decrease the absorbance at $517 \mathrm{~nm}$ by $50 \%$ [14].

\section{Superoxide Free Radical Scavenging Activity}

The superoxide radical was detected by NBT reduction. The reaction mixture contained EDTA $(0.1 \mathrm{M}), 0.0015 \% \mathrm{NaCN}$, riboflavin $(0.12 \mathrm{mM})$, NBT $(1.5 \mathrm{mM})$ and various concentrations of extract and phosphate buffer $(67 \mathrm{mM}, \mathrm{pH} 7.8)$ in a total volume of $3 \mathrm{ml}$. The tubes were uniformly illuminated for $15 \mathrm{~min}$ and optical density was measured at $530 \mathrm{~nm}$ before and after the illumination. The percentage inhibition was calculated by using equation 1 [15].

\section{Anti-Lipid Peroxidation Assay}

A modified thiobarbituric acid-reactive species assay was used to measure the lipid peroxide formed. Plant extract of $0.6 \mathrm{ml}$ of extract were added to a test tube and made up to $1 \mathrm{ml}$ with distilled water. $0.005 \mathrm{ml}$ of FeSO4 $(0.07 \mathrm{M})$ was added to induce lipid peroxidation and incubated for $30 \mathrm{~min}$. Then $1.5 \mathrm{ml}$ of $20 \%$ acetic acid, $1.5 \mathrm{ml}$ of $0.8 \%$ (w/v) TBA in $1.1 \%$ sodium dodecyl sulphate and $0.5 \mathrm{ml} 20 \%$ TCA were added and the resulting mixture was vortexed and then heated at $950 \mathrm{C}$ for $60 \mathrm{~min}$. If the sample have high amount of anthocyanin then to eliminate this non-MDA interference, another set of samples were treated in the same way, incubating without TBA. After cooling, $5.0 \mathrm{ml}$ of butanol were added to each tube and centrifuged at $3000 \mathrm{rpm}$ for $10 \mathrm{~min}$. The absorbance of the organic upper layer was measured at $532 \mathrm{~nm}$. Incubation of lipid peroxidation $(\%)$ by the extract was calculated according to the equation 1 [16].

\section{$\mathrm{H}_{2} \mathrm{O}_{2}$ Radical Scavenging Assay}

A solution of hydrogen peroxide $(2 \mathrm{mmol} / \mathrm{l})$ was prepared in phosphate buffer ( $\mathrm{pH} 7.4)$ to which the extracts $(1-10 \mu \mathrm{g} / \mathrm{ml})$ were added to hydrogen peroxide solution $(0.6 \mathrm{ml})$. After incubation for 10 mins, the absorbance of hydrogen peroxide was measured at 230 nm. Phosphate buffer without hydrogen peroxide was used as blank and it is compared with ascorbic acid as the reference compound. The percentage inhibition was calculated by using equation 1 [17] .

\section{Results and Discussion}

\section{Synthesis of Gold Nanoparticles}

The synthesis of gold nanoparticles can be found within an hour (50 minutes) when cherry red colour solution was obtained 
Table.1 Phytochemical Composition of Aqueous and Methanolic

Extracts of Silybum marianum

\begin{tabular}{|c|c|c|}
\hline Phytochemical compounds & Aqueous extracts & Methanolic extracts \\
\hline Sugars & Positive & Positive \\
\hline Tannins & Negative & Positive \\
\hline Flavanoids & Negative & Positive \\
\hline Alkaloids & Positive & Positive \\
\hline Terpenoids & Negative & Positive \\
\hline Anthocyanins & Negative & Positive \\
\hline
\end{tabular}

Figure.1 DPPH Free Radical Scavenging Activity of Methanol Extracts of Silybum marianum

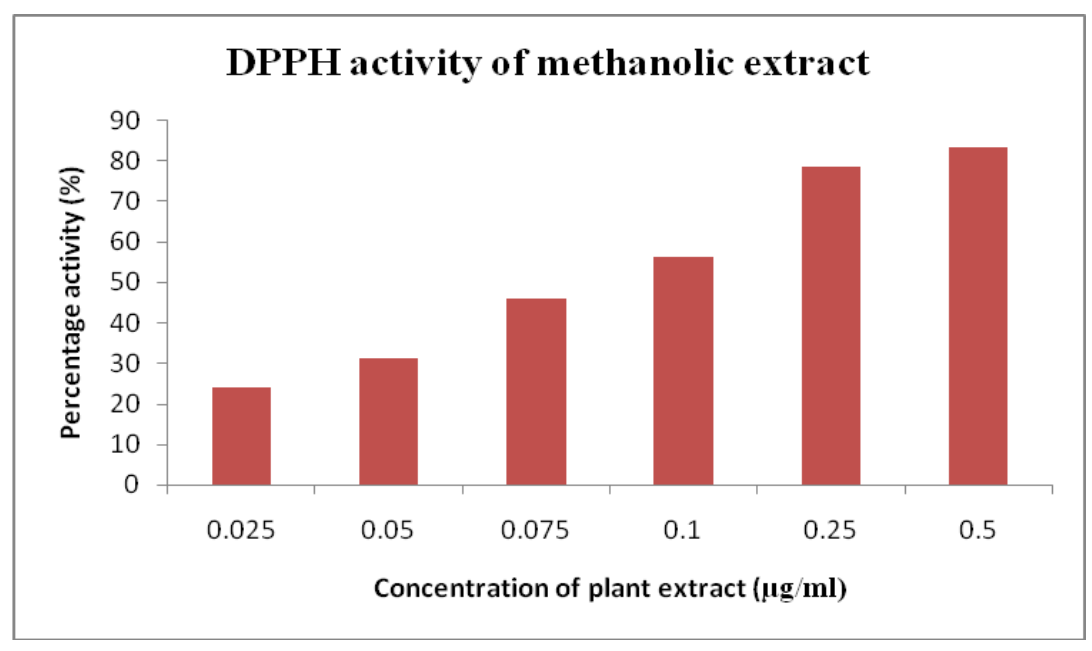

Figure.2 Superoxide Free Radical Scavenging Activity of Methanol Extracts of Silybum marianum

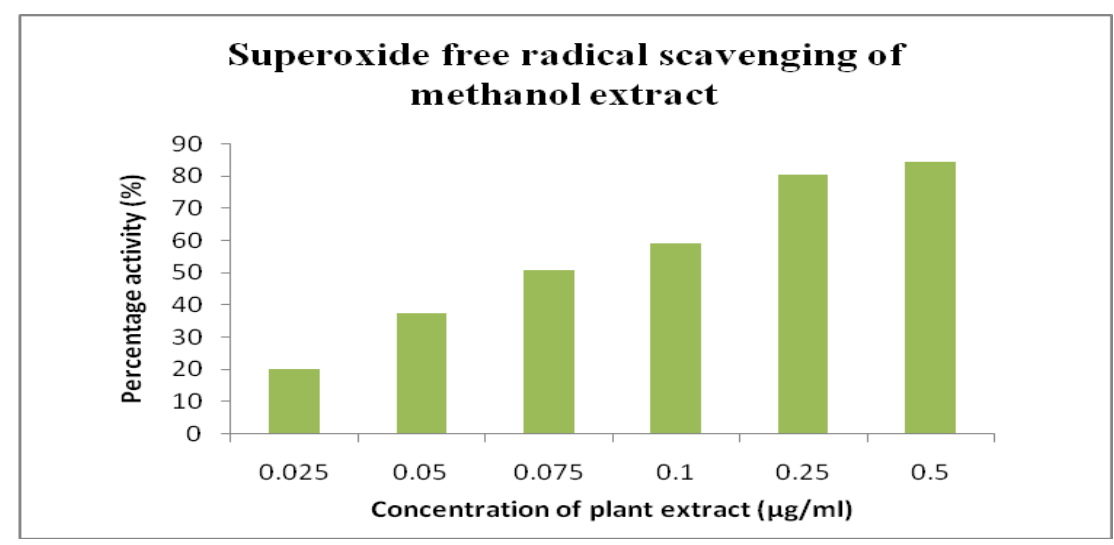


Figure.3 Anti Lipid Peroxidation Activity of Methanol Extracts of Silybum marianum

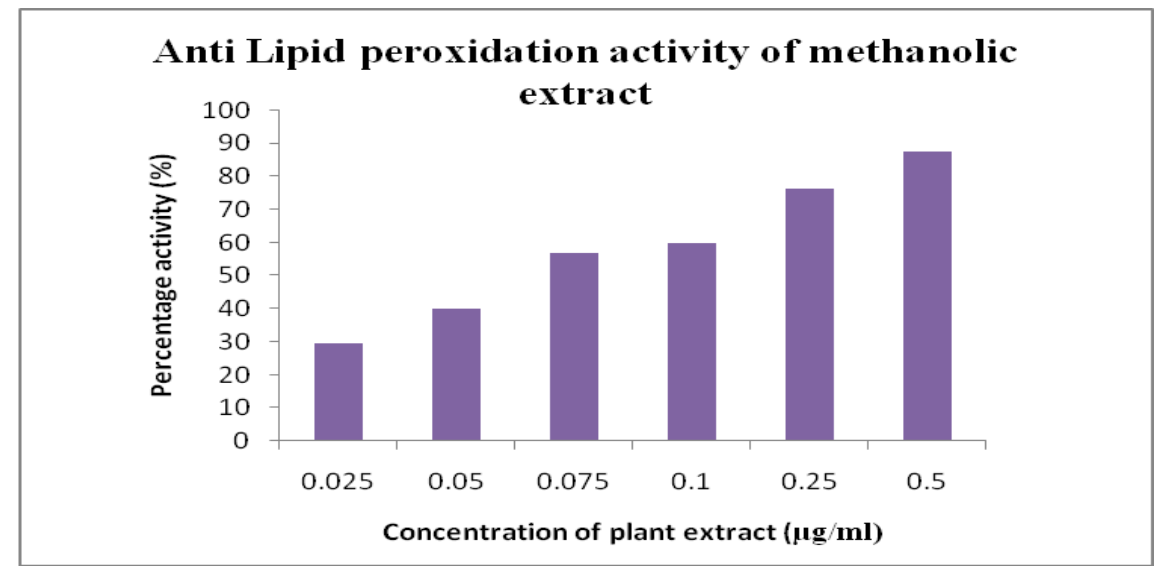

Figure.4 Hydrogen Peroxidase scavenging Activity of Methanol Extracts of Silybum marianum

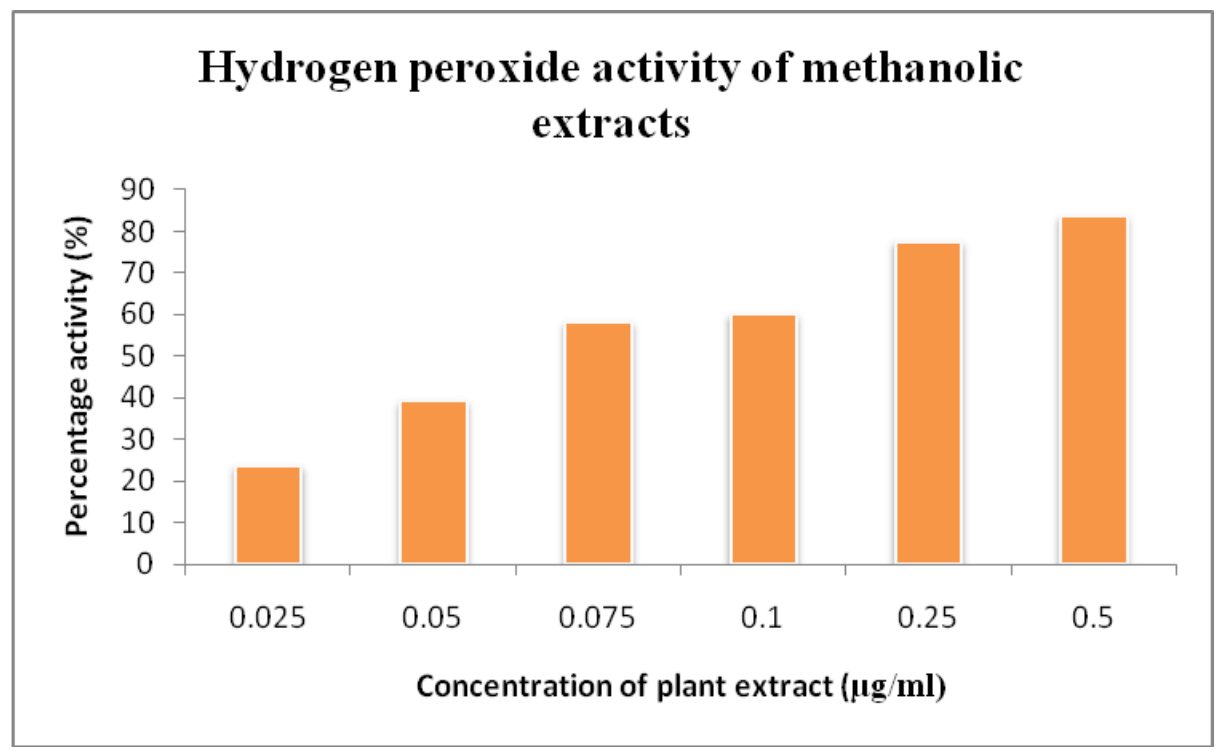

\section{Phytochemical Analysis of Plant Extracts}

The aqueous and methanolic extracts of the plant Silybum marianum has been used to find the bioactive compounds present in the plant. The Phytochemical tests for sugars, tannins, flavanoids, alkaloids and terpenoids shows that the plant has more bioactive compound in its methanolic extract than the aqueous extract. Therefore the methanolic extract has been taken for further study. Table 1 shows the presence of compounds in methanolic and aqueous extracts.

\section{Free Radical Scavenging Activity}

The free radical scavenging activity of the methanolic extracts done by DPPH free radical scavenging activity, Superoxide radical scavenging activity, Anti-lipid peroxidation assay and Hydrogen peroxide assay was shown in Figure 1, 2, 3 and 4 respectively and was found to have notable antioxidant activity. It has also been noticed that there is increased activity with increase in concentration of the extract. Similar 
results were noticed by several works done on antioxidant activity of plant extracts [15, $16,17]$.

\section{References}

1. Jennifer scalf and Paul west, Pacific nanotechnology, Introduction to nanoparticle characterization with AFM, $1-9$.

2. Kikuo Okuyama, Wuled Lenggoro and Toru Iwaki, Nanoparticle Preparation and Its Application - A Nanotechnology Particle Project in Japan, Proceedings of the 2004 International Conference on MEMS, NANO and Smart Systems (ICMENS'04), IEEE, 2004, 1 - 4.

3. Nagaraj Basavegowda, Agnieszka Sobczak-Kupiec, Dagmara Malina, Yathirajan HS, Keerthi V R, Chandrashekar N, Salman Dinkar, Liny $\mathrm{P}$, Plant mediated synthesis of gold nanoparticles using fruit extracts of ananas comosus (L.) (pineapple) and evaluation of biological activities, Adv. Mat. Lett. 2013, 4(5), 332-337.

4. Probin Phanjom, Azmin Sultana, Himakshi Sarma, Jahnabi Ramchiary, Kongkana Goswami, Pitambar Baishya, Plant-mediated synthesis of silver nanoparticles using elaeagnus latifolia leaf extract, Digest Journal of Nanomaterials and Biostructures, 7 (3), 2012, $1117-1123$.

5. R.Sarada, Dr. V. Jagannadharao, Prof B.Shyama Sunder, Plant Mediated Synthesis of Silver Nanoparticles by Using Dried Stem Powder of Tinospora Crispa, And Study of Its Photoluminiscence Activity, Int. Journal of Engineering Research and Applications, 5(7), 2015,82-89.

6. P.Kathireswari, S.Gomathi and K.Saminathan, Plant leaf mediated synthesis of silver nanoparticles using
Phyllanthus niruri and its antimicrobial activity against multi drug resistant human pathogens, Int.J.Curr.Microbiol.App.Sci (2014) 3(3): 960-968.

7. Ratul Kumar Das, Nayanmoni Gogoi, Punuri Jayasekhar Babu, Pragya Sharma, Chandan Mahanta, Utpal Bora, The Synthesis of Gold Nanoparticles Using Amaranthus spinosus Leaf Extract and Study of Their Optical Properties, Advances in Materials Physics and Chemistry, 2012, 2, 275-281.

8. Sree Gayathri S., and Dr. Racheal Regi Daniel, A plant -mediated synthesis of silver \& gold nanoparticles and their characterization using aqueous leaf extract of selected medicinal trees, International Journal of Current Research, 4(12), 2012, 509-514.

9. P. Shanmuga Praba, V. S.Vasantha, J . Jeyasundari and Y. Brightson, Arul Jacob, Synthesis of plant-mediated silver nanoparticles using ficus microcarpa leaf extract and evaluation of their antibacterial activities, Eur. Chem. Bull., 2015, 4(3), 116-120.

10. Silybum marianum, Alternative Medicine Review Monographs, 1999, 4(4), $272-274$.

11. M. Ozturk, M. Akdogan, I. Keskin, A.N. Kisioglu, S. Oztas and K. Yildiz, Effect of Silybum marianum on acute hepatic damage caused by carbon tetrachloride in rats, Biomedical Research 2012; 23 (2): 268-274.

12. Abdul Wadood, Mehreen Ghufran, Syed Babar Jamal, Muhammad Naeem, Ajmal Khan, Rukhsana Ghaffar and Asnad, Phytochemical Analysis of Medicinal Plants Occurring in Local Area of Mardan, Biochem Anal Biochem 2013, 2- 4.

13. Satheesh Kumar Bhandary, Suchetha Kumari N. , Vadisha S. Bhat, Sharmila 
K.P., Mahesh Prasad Bekal, Preliminary phytochemical screening of various extracts of punica granatum peel whole fruit and seeds, NUJHS, 2(4), 2012, 1-5.

14. Adriana Maria Fernandes de Oliveira, Lilian Sousa Pinheiro, Charlane Kelly Souto Pereira, Wemerson Neves Matias, Roosevelt Albuquerque Gomes, Otemberg Souza Chaves, Maria de Fátima Vanderlei de Souza, Reinaldo Nóbrega de Almeida and Temilce Simões de Assis, Total Phenolic Content and Antioxidant Activity of Some Malvaceae Family Species, Antioxidants 2012, 1, 33-43.

15. Pratap Chandran R, Vysakhi M.V, Manju S, Kannan M, Abdul Kader S And Sreekumaran Nair A, In vitro free radical scavenging activity of aqueous and methanolic leaf extracts of aegle tamilnadensis abdul kader (rutaceae), International Journal of Pharmacy and
Pharmaceutical Sciences, 5(3), 2013, 819-823.

16. Engoor Sugathakumar Adithya, Mangalanandan Santha Lakshmi, Paul Hephzibah Christabel and Jagathala Mahalingam Sasikumar, In vitro antioxidant, anti-lipid peroxidation activities and HPLC analysis of methanol extracts from bark and stem of Mahonia leschenaultia takeda, Asian Journal of Plant Science and Research, 2013, 3(2):116-126.

17. Saumya S M \& Mahaboob Basha P, In vitro evaluation of free radical scavenging activities of panax ginseng and lagerstroemia speciosa: a comparative analysis, International Journal of Pharmacy and Pharmaceutical Sciences, 3(1), 2011, 165-169.

\section{How to cite this article:}

Kosalai, D., and Chandran, M. 2016. Phytochemical Analysis and Anti-Oxidant Activity of Gold Nanoparticles Synthesizing Plant - Silybum marianum. Int.J.Curr.Microbiol.App.Sci.5(4): 469-475. doi: http://dx.doi.org/10.20546/ijcmas.2016.504.055 